\title{
Synthesis of Functionalized RAFT Agents for Light Harvesting Macromolecules
}

\author{
Ming Chen, ${ }^{\dagger}$ Kenneth P. Ghiggino, ${ }^{* \dagger}$ Albert W. H. Mau, Ezio Rizzardo, ${ }^{*}$ Wolfgang H. F. Sasse, \\ San H. Thang, ${ }^{*}$ and Gerard. J. Wilson ${ }^{*}$
}

'School of Chemistry, The University of Melbourne, Victoria 3010, Australia.

${ }^{*}$ CSIRO Molecular Science, Bag 10, Clayton South, Victoria 3169, Australia.

ghiggino@unimelb.edu.au

RECEIVED DATE (to be automatically inserted after your manuscript is accepted if required according to the journal that you are submitting your paper to)

\section{Supporting Information}

\section{Experimental details}

Materials. Coumarin 2 (Laser dye grade) was purchased from Exciton. Acenaphthylene (Rütgers) was recrystallized three times from methanol. All other starting materials were obtained from Aldrich, and were used as received. Solvents used for absorption and fluorescence measurements were spectroscopic grade.

General methods. ${ }^{1} \mathrm{H}$ and ${ }^{13} \mathrm{C}$ NMR spectra were obtained on a Bruker Av400 or DRX500 spectrometer in the solvents indicated. Positive ion Electron Impact (EI) mass spectra were run on a ThermoQuest MAT95XL mass spectrometer using an ionization energy of 70eV. UV-vis absorption spectra were recorded on a Varian 50 Bio-spectrophotometer. Steady state fluorescence spectra were 
recorded on a Varian Cary Eclipse fluorometer. The optical density of the solutions for fluorescence measurements was kept below 0.15 at the excitation wavelength. Fluorescence and excitation spectra were corrected for the wavelength dependence of detector sensitivity and excitation light source output. Molecular weight data were obtained by gel permeation chromatography (GPC). Tetrahydrofuran (1.0 $\mathrm{mL} / \mathrm{min}$ ) was used as eluent. The GPC was calibrated with narrow polydispersity polystyrene standards, and molecular weights are reported as polystyrene equivalents.

\section{Synthesis of RAFT-Coumarin}

A mixture of 2-cyanoprop-2-yl dithiobenzoate ${ }^{1}$ (1.0 g, $\left.4.5 \mathrm{mmol}\right)$, St-Coumarin $^{2}$ (1.5 g, $\left.4.5 \mathrm{mmol}\right)$, AIBN (0.014 g, $0.090 \mathrm{mmol})$ and chlorobenzene $(2.0 \mathrm{~mL})$ was degassed through three freeze-pumpthaw cycles, sealed under vacuum, and heated in a $70^{\circ} \mathrm{C}$ oil bath for $24 \mathrm{~h}$. After purification by column chromatography, a red solid (2.0g) was obtained (85\% yield). ${ }^{1} \mathrm{H} \mathrm{NMR}\left(500 \mathrm{MHz}, \mathrm{CDCl}_{3}, \mathrm{ppm}\right): \delta 1.03$ (t, 3H, -CH3), 1.21 (s, 3H, -CH3), 1.41 (s, 3H, -CH3), $2.30-2.45$ (m, 8H, $2 \times-\mathrm{CH} 3+-\mathrm{CH} 2-), 3.03$ (q, 2H, -N-CH2-), 4.18 (s, 2H, -Ar-CH2-N), 5.32 (q, 1H, -S-CH(Ar)-), 6.12 (s, 1H, =CH-), 6.88 - 7.94 (m, $11 \mathrm{H}$, ar.). ${ }^{13} \mathrm{C}$ NMR (100MHz, $\mathrm{DCCl}_{3}$-d3, ppm): $\delta 225.9,161.8,153.9,152.85,152.54,144.9,138.8$, $137.6,132.8,129.7,128.9,128.8,128.6,127.2,126.7,124.1,115.0,112.8,109.5,56.6,52.2,46.5$, 45.1, 32.0, 28.0, 27.1, 18.9, 18.8, 12.0. EI-MS: 554 (20, M+), 401 (65), 184 (50), 121 (74), 117 (100), 77 (14). UV-Vis $\left(\mathrm{CH}_{2} \mathrm{Cl}_{2}\right): \lambda_{\max }(\log \varepsilon): 307$ (shoulder, 4.27), $339 \mathrm{~nm}$ (4.30), $500 \mathrm{~nm}$ (2.08).

\section{Synthesis of $\mathrm{P}(\mathrm{AcN})$-Coumarin by RAFT polymerization}

A mixture of RAFT-Coumarin (0.036 g, $0.066 \mathrm{mmol})$, AIBN (0.001 g, $0.007 \mathrm{mmol})$, acenaphthylene $(1.0 \mathrm{~g}, 6.6 \mathrm{mmol})$ and chlorobenzene $(1.5 \mathrm{~mL})$ was degassed through three freeze-pump-thaw cycles, sealed under vacuum, and heated at $70^{\circ} \mathrm{C}$ for $24 \mathrm{~h}$. The polymer was then precipitated by addition to 20 $\mathrm{mL}$ of methanol, redissolved in $1 \mathrm{~mL}$ chlorobenzene and reprecipitated in methanol, filtered and dried under vacuum to give $0.260 \mathrm{~g}$ polymer. The conversion yield was $22.0 \%$. GPC instrumentation calibrated using linear polystyrene standards is not expected to provide accurate values of $M_{n}$ and $M_{w}$ 
for poly(acenaphthylene), as noted earlier. ${ }^{3}$ The molecular weights of the polymer obtained by the different techniques are summarized in Table 1.

Table1. Polymer molecular weights determined by various methods

\begin{tabular}{|c|c|c|c|}
\hline \multicolumn{2}{|c|}{ By GPC } & \multirow{2}{*}{$\mathrm{M}_{\mathrm{n}}$ by $\mathrm{UV}^{\mathrm{a}}$} & \multirow{2}{*}{$\mathrm{M}_{\mathrm{n}}$ by calculation ${ }^{\mathrm{b}}$} \\
\hline $\mathrm{M}_{\mathrm{n}}$ & $\mathrm{M}_{\mathrm{w}} / \mathrm{M}_{\mathrm{n}}$ & & \\
\hline 2300 & 1.10 & 4000 & 3900 \\
\hline
\end{tabular}

${ }^{a}$ In the UV method, the absorption spectrum of the polymer solution is compared to the absorption of solutions of known concentrations of homo poly(acenaphthylene) and RAFT-Coumarin at 297 and $345 \mathrm{~nm}$ respectively.

${ }^{\mathrm{b}}$ Theoretical molecular weights were calculated using the expression $\mathrm{M}_{\mathrm{n}}$ (calc) $=([\mathrm{monomer}] /[\mathrm{RAFT}$ agent $]) \times$ fractional conversion $\times$ MWt of monomer + MWt of RAFT agent. This expression does not include the small number of chains formed from the initiator. It also assumes complete consumption of RAFT agent.

\section{Synthesis of P(AA)-b-P(AcN)-Coumarin by RAFT polymerization}

A mixture of acrylic acid (0.562 g, $13.90 \mathrm{mmol})$, AIBN (0.0005 g, $0.0033 \mathrm{mmol}), \mathrm{P}(\mathrm{AcN})$-Coumarin (0.050 mg, $0.013 \mathrm{mmol}$ equivalent RAFT-Coumarin) and dimethylformamide (1.5 mL) was degassed through three freeze-pump-thaw cycles, sealed under vacuum, and heated at $65{ }^{\circ} \mathrm{C}$ for $16 \mathrm{~h}$. The solution was dialyzed against water for 2 days using a Pierce Dialysis Cassette with MWCO equal to 3500. The colour of the polymer solution changed from orange to colourless as the dithiobenzoyl is hydrolyzed during the dialysis process. The polymer solution was then freeze-dried and $0.330 \mathrm{~g}$ polymer was obtained.

\section{Synthesis of $\mathrm{P}(\mathrm{AcN})$-IBN by conventional free radical polymerization}

A mixture of AIBN (0.005 mg, $0.033 \mathrm{mmol})$, acenaphthylene $(1.0 \mathrm{~g}, 6.6 \mathrm{mmol})$ and chlorobenzene $(1.0$ $\mathrm{mL}$ ) was degassed through three freeze-pump-thaw cycles, sealed under vacuum, and heated at $70^{\circ} \mathrm{C}$ for $16 \mathrm{~h}$. The mixture was cooled and precipitated twice into $20 \mathrm{~mL}$ of methanol to give $0.420 \mathrm{~g}$ of the required polymer as precipitate. The conversion yield was $50.0 \% . M_{n}=15900, M_{w} / M_{n}=1.6$. 


\section{Spectra of polymers}

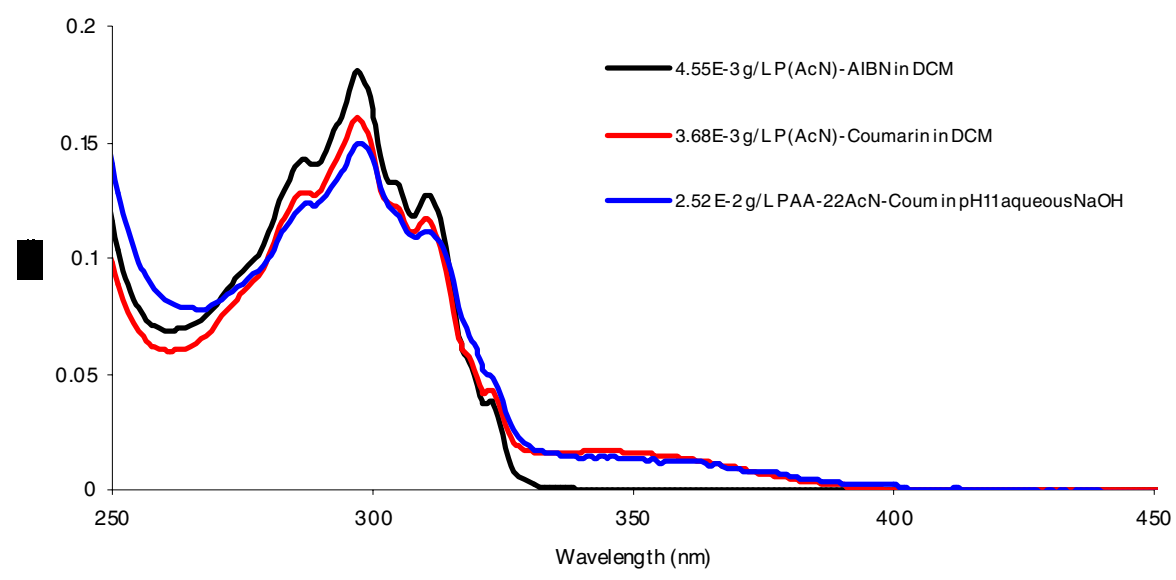

Figure 1. The absorption spectra of polymer solutions.

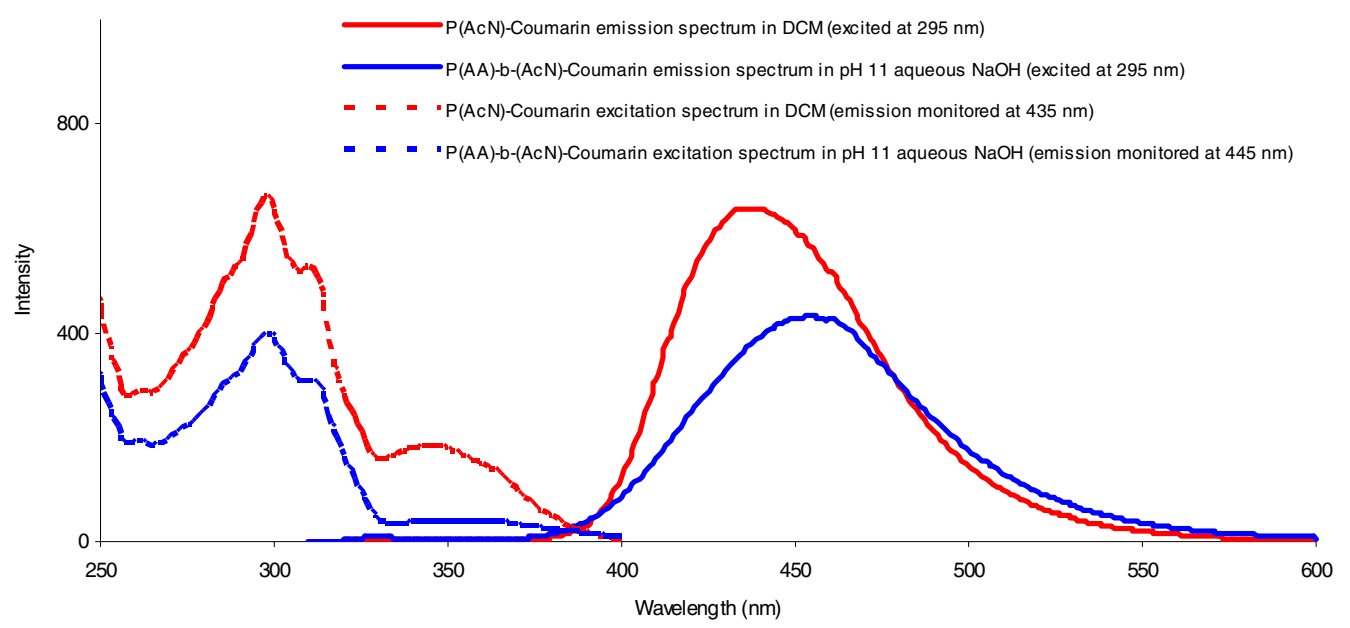

Figure 2. The emission and excitation spectra of $\mathrm{P}(\mathrm{AcN})$-Coumarin in dichloromethane (DCM) and P(AA)-b-(AcN)-Coumarin in $\mathrm{pH} 11$ aqueous $\mathrm{NaOH}$.

Energy transfer efficiencies from acenaphthyl groups to the coumarin terminal were determined by comparison of corrected excitation spectra and the absorption spectra of the polymers as described previously. $^{3}$

\section{References:}


1. Thang, S. H.; Chong, Y. K.; Mayadunne, R. T. A.; Moad, G.; Rizzardo, E. Tetrahedron Lett., 1999, 40, 2435

2. Schultze, X.; Serin, J.; Adronov, A.; Fréchet, J. M. J. Chem. Commun., 2001, 1160

3. Chen, M.; Ghiggino, K. P.; Mau, A. W. H.; Rizzardo, E.; Thang, S. H.; Wilson, G. J. Chem. Commun., 2002, 2276-77. 